\title{
LA PRENSA DECIMONÓNICA Y DEL SIGLO XX EN LA DIFUSIÓN DEL PATRIMONIO ARQUEOLÓGICO. ¿RELACIONES INTERDISCIPLINARES?
}

\section{THE 19TH AND 20TH CENTURY PRESS IN THE DISSEMINATION OF ARCHAEOLOGICAL HERITAGE. INTERDISCIPLINARY RELATIONSHIPS?}

\author{
Salomé Zurinaga Fernández-Toribio* \\ Museo Arqueológico Nacional
}

\begin{abstract}
RESUMEN. El presente trabajo traza un recorrido por algunos periódicos locales y nacionales de los siglos XIX y XX (hasta 1982), con una breve parada en revistas ilustradas, a través de algunos casos cuyo hilo conductor común es la difusión de la práctica arqueológica en la prensa escrita. Partiendo del nacimiento y evolución de la ciencia arqueológica y el establecimiento de la disciplina periodística, examinamos si existen relaciones interdisciplinares entre ambos temas. Algunos de los periódicos revisados que abordan la preservación y difusión del patrimonio cultural nos llevan a diferentes lugares como Granada, Sóller, Mérida, Nubia y Orce. Todos ellos cumplieron su tarea informativa sobre los nuevos hallazgos arqueológicos que tuvieron lugar, ya fueran hallazgos casuales o excavaciones sistemáticas.
\end{abstract}

PALABRAS CLAVE: Prensa escrita, revistas ilustradas, siglo xIx, siglo xx, divulgación arqueológica, relaciones interdisciplinares.

ABSTRACT. The present work traces a tour through some local and national Spanish newspapers of the 19th and 20th centuries (up to 1982), and a brief stop in illustrated magazines, through some cases whose common thread is the dissemination of archaeological practice in the written press. On the basis of the progress of archaeological science and the establishment of journalistic discipline, we examine whether there are interdisciplinary relationships between the two issues. The reviewed newspapers that addressed the preservation and dissemination of cultural heritage bring us to different places such as Granada, Sóller, Mérida, Nubia and Orce. All of them fulfilled their informative task about the new archaeological finds that took place whether they were casual findings or systematic excavations.

KEYWORDS: Written press, illustrated magazines, 19th century, 20th century, archaeological dissemination, interdisciplinary connections.

\footnotetext{
* Correspondencia a / Correspondence to: Salomé Zurinaga Fernández-Toribio, Museo Arqueológico Nacional - salome.zurinaga@cultura.gob.es https://orcid.org/0000-0002-3109-9790.

Cómo citar / How to cite: Zurinaga Fernández-Toribio, S. (2020), «La prensa decimonónica y del siglo Xx en la difusión del patrimonio arqueológico. ¿Relaciones interdisciplinares?», Veleia, 37, 157-175. (https://doi.org/10.1387/veleia.20967).
}

Recibido: 14 octubre 2019; aceptado: 29 noviembre 2019

ISSN 0213-2095 - elSSN 2444-3565 / (C) 2020 UPV/EHU 


\section{INTRODUCCIÓN}

El interés que el ser humano ha mostrado hacia los vestigios del pasado no es nuevo y esa atención, de una manera u otra, siempre ha estado ahí, en forma de atesoramiento de cosas curiosas, raras, exóticas, naturalia y todo tipo de regalías, cuando no de recogida de restos arqueológicos y paleontológicos. No es tan moderno informar sobre el patrimonio arqueológico, lo que sí lo es, son los formatos y soportes que han evolucionado, y las formas de emitir las noticias cuando ponen el foco en los hallazgos arqueológicos. Informar sobre la aparición de antigüedades se ha hecho desde hace centurias, en el siglo XVIII a través de las gacetas, repertorios y reportajes. En el XIX, aparecen informaciones sobre hallazgos en revistas, sueltos y semanarios, y en el siglo xx en periódicos, enciclopedias ilustradas a todo color, y otros formatos como la prensa digital. Independientemente de las etapas por las que ha pasado el periodismo moderno espańol: ideológico, informativo, de explicación (Hernández Márquez 2001, 67), su estudio revela que la arqueología es uno de los temas a los que los medios de comunicación dedican más espacio «noticioso y divulgativo» (Meneses Fernández 2011, 366). Las noticias arqueológicas han resultado siempre muy «vendibles». Por ello, es muy interesante saber la manera en que se ha informado sobre ellas para conocer el impacto que ha tenido en la sociedad. Es este sentido, podemos decir que el periodismo ha sido la llave o tarjeta de visita que muchos lectores han necesitado para acercarse en profundidad a un tema cultural ignoto. Los canales seguidos han sido el del periódico diario, ya fuera matutino o vespertino.

Nuestro estudio es solo una muestra del potencial que tiene este campo de investigación, pudiendo servir de base a estudios posteriores que de manera más amplia aborden las relaciones entre dos saberes tan diferentes como complementarios como son los aquí esbozados. Desde sus inicios han ido de la mano. La fecha final escogida en el estudio - los años 80-, obedece a que el caso de Orce fue paradigmático por la controversia y el tratamiento periodístico que recibió, razón suficiente dado que sirvió de punto de reflexión para que ambas comunidades, la científica y la periodística afrontaran la difusión de los hallazgos de otra manera más comprometida y menos sensacionalista.

En la prensa, la imparcialidad es uno de los principios por los que se debe regir el periodista que cubre la noticia, elabora una crítica o realiza un reportaje, si bien a veces resulta difícil no caer en la subjetividad y sensacionalismo con un periodismo muy personalista reflejo de la opinión del que escribe, aunque a veces, la difusión de los trabajos arqueológicos va acompañada de una carga política y simbólica que no ocultan sus promotores. Sobre determinados hallazgos se han publicado multitud de artículos que constatan los vaivenes de lo ibérico, lo celta, lo patrio, lo local, o nacionalista, en pos de los intereses de unos y otros, por lo que no nos vamos a detener (Álvarez-Sanchís \& Ruiz Zapatero 1998, Díaz-Andreu \& Mora 1995). En la actualidad no se oculta la manipulación hecha sobre el patrimonio, usado como arma arrojadiza dependiendo de la coyuntura política y el partidismo de la prensa en su divulgación (Penedo Cobo \& Caballero Casado 2009, 425, 437, 440). La prensa de ayer y la de hoy ha respondido siempre a tintes ideológicos, ilustrando, pero también creando opinión (Gómez-Barrera 2008, 460-461). A principios del siglo xx, la arqueología española se consolidó como ciencia, sentándose sus bases, definiéndose sus límites y regulándose por las leyes de 1911, 1926, 1933 y 1985. La prensa, sabedora de este nuevo interés, recogerá muy de cerca las intervenciones arqueológicas, como fue la recuperación del teatro romano de Mérida (Morán Sánchez 2013). Llama la atención que, a pesar del interés institucional, de gobiernos, academias y sociedad, se produjese en estos ańos una venta continua de patrimonio (Gómez Alfeo 1997, 541). A nivel formal uno de los males 
del periodismo es la reiteración de tópicos y errores que se arrastran y se reiteran sin cesar (Morán Sánchez 2013, 2187-2188, Zurinaga Fernández-Toribio 2012, 398), ya sea por desconocimiento del cómputo cronológico y el devenir de la Historia, como observa Caballero en relación a unas noticias publicadas en Por esos Mundos y Nuevo Mundo (Caballero Rodríguez 2008, 225). También se detectan errores sintácticos y gramaticales siendo el caso de la prensa sobre Nubia en los años sesenta del siglo xx el más conocido por mí, pero la mayoría corresponden a errores de trascripción y otros, que hoy en día consideraríamos errores, eran lo normal en la época: la espańolización de nombres propios (Zurinaga Fernández-Toribio 2009a, 124, 188; Zurinaga Fernández-Toribio 2009b, 48).

En la actualidad el proyecto del Ministerio de Cultura y Deporte, con la Biblioteca Virtual de Prensa Histórica de digitalización de periódicos españoles es de innegable ayuda, al facilitar el acceso universal a la prensa histórica; de la misma manera que desde la página web de la Hemeroteca Digital de la Biblioteca Nacional. Por su parte, desde las publicaciones la Sociedad Española de Historia de la Arqueología (SEHA), se realiza una gran labor de difusión de la historia de la arqueología a través de la revista $A R C H A I A$ y el boletín de la SEHA, el GAZSEHA (Salas Álvarez 2015, 254).

El interés por la historia de la arqueología resulta algo tardío en nuestro país, aunque últimamente se han sucedido nuevos estudios en esta línea, y más novedosos resultan los estudios que relacionan la conexión de la arqueología con el periodismo. Desde hace pocos años se vienen realizando trabajos descriptivos y recopilatorios que abordan la aparición de noticias arqueológicas en la prensa escrita. Nos encontramos los que focalizan la atención en una región geográfica concreta o en un hecho histórico-arqueológico determinado. Como el marco de este trabajo llega hasta los años 80 del pasado siglo, reseñamos solo algunos como los de Matías-Cruz (2014) sobre la visión del patrimonio histórico y la arqueología cordobesa; los de Arranz (2018), que analiza las noticias arqueológicas referidas a Próximo Oriente (Egipto y Mesopotamia), Grecia, Roma y España, entre los siglos XIX y Xx en la prensa escrita. O los de Zurinaga (Zurinaga Fernández-Toribio 2009a; 2009b; 2012; 2015) sobre la Campaña de Nubia de la UNESCO y su impacto en la prensa escrita.

\section{LAS INCURSIONES ARQUEOLÓgICAS DE LA PRENSA DECIMONÓNICA}

El tratamiento de la arqueología en la prensa escrita viene de lejos. Fueron los descubrimientos de Heinrich Schliemann acerca de la ciudad de Troya, comenzada a excavar en 1870, los que dejaron patente la importancia de una emergente historia que debía ser contada a través de los periódicos (Figura 1). Elegir tal medio informativo acercaba de manera masiva al público ordinario lo que de otro modo hubiera quedado reducido al conocimiento de un público especializado. 


\begin{tabular}{|c|c|c|c|}
\hline SUPPLEMENT, APRIL 28, 1877.$]$ & HARPEP & WEEK & 337 \\
\hline 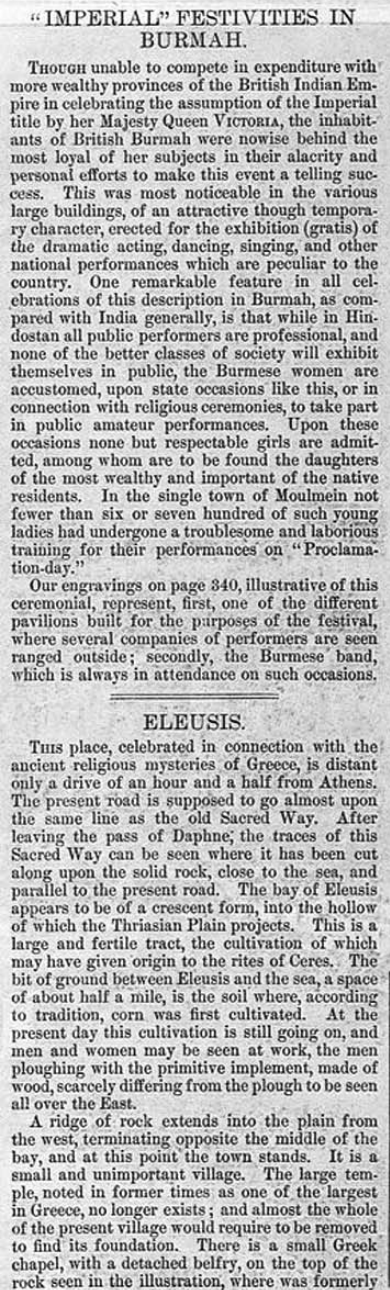 & 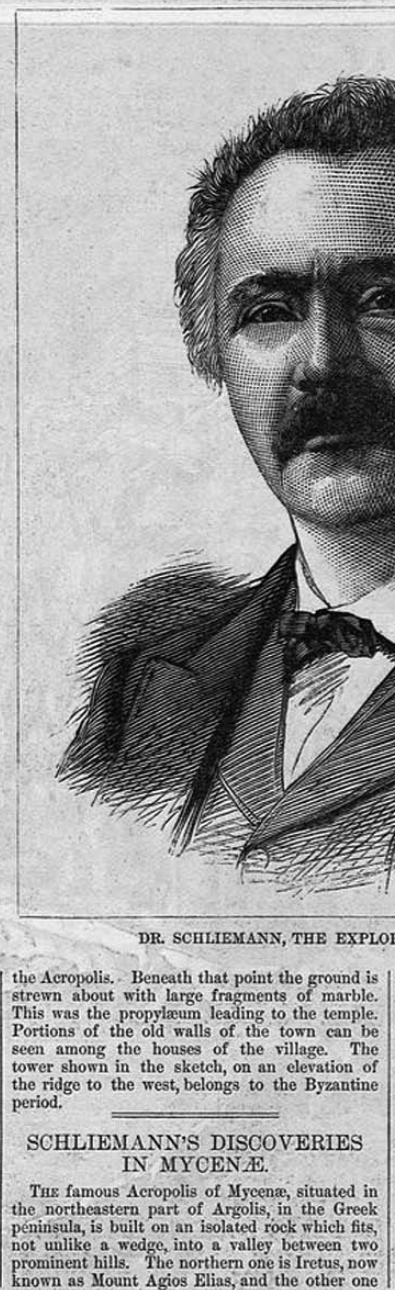 & $\begin{array}{l}\text { as Sara. The rocky scarp of the citadel toward } \\
\text { the last-named hill is so precipitous that no at. } \\
\text { tack would have been likely on that side. Still } \\
\text { there are remains of huge walls now standing in } \\
\text { places where the cliff is less perpendicular. On } \\
\text { the other side, which was easier of approach, a } \\
\text { long wall of the most enduring masonry extended } \\
\text { the whole length. This terminated at one end } \\
\text { where the rocky point of the wedge looked to the } \\
\text { east up the valley, and at the other where the } \\
\text { wall turned to the southeast, forming one side of } \\
\text { the approach to the famous Lion Gateway, thus } \\
\text { named from the figures over the doorway of two } \\
\text { lions, which act as supports on each side of a } \\
\text { pillar. From this gateway the wall is again con- } \\
\text { tinued pretty nearly southwest for a short dis. } \\
\text { tance, when it turns with an angle to the south. } \\
\text { east, in which direction it runs on again until it }\end{array}$ & 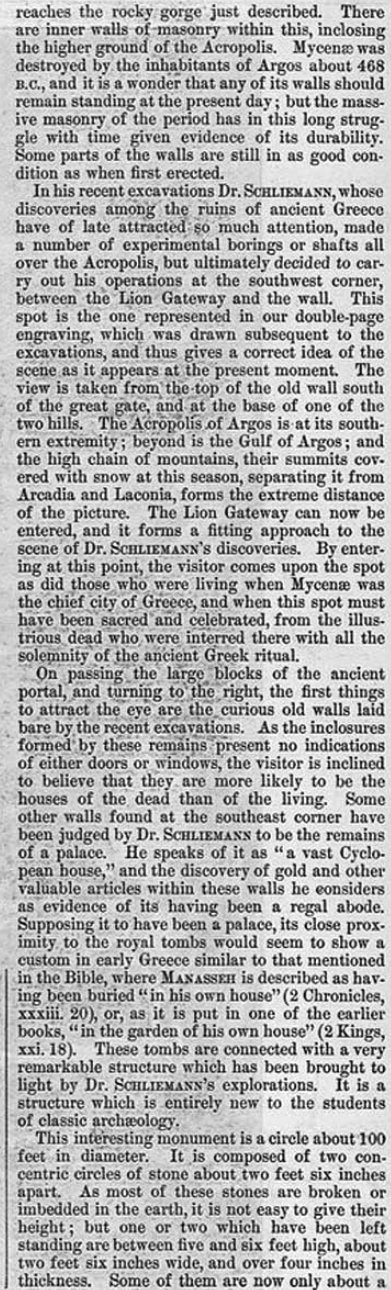 \\
\hline
\end{tabular}

Figura 1. Recorte de prensa sobre el hallazgo del tesoro de Troya por Heinrich Schliemann publicado en el semanario Harper's Weekly, en 1877.

En el último tercio del siglo xix la sociedad se implicará en la preservación del patrimonio a través de sus eruditos (Vallejo Girvés 2012, 227). La prensa, por su parte, contribuyó a la recuperación del patrimonio cultural del que se harán eco las rotativas de las grandes ciudades y de las localidades pequeñas, al contar casi todos los municipios con su propio periódico, hecho que se expandirá hasta el primer tercio del siglo $\mathrm{xx}$, por toda la península, con una activa prensa de provincias (Gómez Alfeo 1997). Los dos primeros registros que aparecen en la base de datos de la Hemeroteca, tras filtrar por los campos «excavación» y "antigüedades», acotando las fechas 01/01/1800-31/12/1825, se refieren a la gaceta Minerva o El Revisor general que informan sobre excavaciones en el exterior. El primero, de 1807, da cuenta de unos descubrimientos en Irlanda (Anónimo 1807, 81), y el segundo, de 1818, sobre Nubia y Egipto. Este último, de 18 de junio, publica una larga carta del explorador y viajero italiano Giovanni Battista Belzoni sobre el trans- 
porte de algunas antigüedades nubias y egipcias (Belzoni 1818). Belzoni dos años más tarde publicaría su conocida obra: Narrative of the Operations and Recent Discoveries within the Pyramids, Temples, Tombs, and Excavations in Egypt and Nubia (Belzoni 1820). Algo después aparecen publicaciones como el Semanario Pintoresco Español (Figura 2), que en 1845 anunciaba la aparición de unas antigüedades en Tarragona (Anónimo 1845). Este tipo de publicaciones históricas han sido analizadas por Tostón, en relación a las Comisiones de Monumentos encargadas, en la época, de la protección del patrimonio arqueológico (Tostón Menéndez 2012).

$320 \quad$ SEMANARIO PINTORESCO ESPAÑOL.

cribanías, bajillas y todo cuanto se emplea con laflde barro; una de ellas cuasi esférica, toda sembraribujos en forma de festones, tres de los cuaplata, siendo una de sus mas sorprendentes partica.

rico metal, pues los ingleses, que son los que lo co- Los trabajos literarios que le ocupan, asi resnocen y lo estraen de nuestro pais, hacen á veces pecto á la descripcion de sus descubrimientos, pasar por plata los efectos en que lo usan. Tiempo como respecto á la obra científica y mecánica, a pas pesti- fin que puedan del modo mas económico y seguro, es, pues enaña; seran taress, que puen tisfaceion en recomendarlo $y$ dart los primeros, ofreciéndonos a dar cuantas mas es- en todo nuestro pais, y entre plicaciones se pidan en la Redaccion de nuestro pe- Entre las personas que sabemos han admirado riódico.

tabilidades siguientes: el Sr. D. Alejandro Olivan

- Antigizedades-Nuestro Corresponsal en Tar

D. Mariano Lopez, el Sr. Marqués de Valgornera,

y el ingeniero Belga Mr. Paul Bonoy, con otros ragona nos escribe lo siguiente.

Ocúpanse con agradable sorpresa, las personas inteligentés de nuestra Capital, en admirar los des cubrimientos arqueológicos que ha verificado de algunos dias á esta parte, el Secretario de este Go bierno Político D. Ivo de la Cortina.

varios que no tenemos presentes.

Nosotros que conocemos el celo, laboriosidad é inteligencia del $\mathrm{Sr}$. Ivo de la Cortina, no podemos menos de hacer públicos sus esfuerzos, para salvar los restos antiguos y presentarlos á la vista del es -

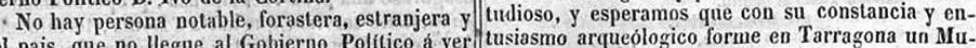
del pais, que no llegue al Gobierno Político á ver tusiasmo arqueologico forme en Tarragona un Mulos objetos preciosos recolectados de todas épocas, seo digno de atencion, auxiliado de la Sociedad Arasi en monedas, idolos, utensilios de márfil, de bar-| qu ros, de bidrio y de cobre.

De Mosaicos ha descubierto cuatro, que unos ha trasladado enteros, $\mathrm{y}$ otros á piezas, de 100 y mas pies en cuadro, á la Iglesia de S. Francisco, donde está el Gobierno Politico.

Pocos dias hà, que ha descubierto tres ánforas es el alma por su actividad y posicion.

MIDRID, 1845: IMPRENTA DE VICENTE DE LALAMA, Calle del Duque deAlba, n. 13.

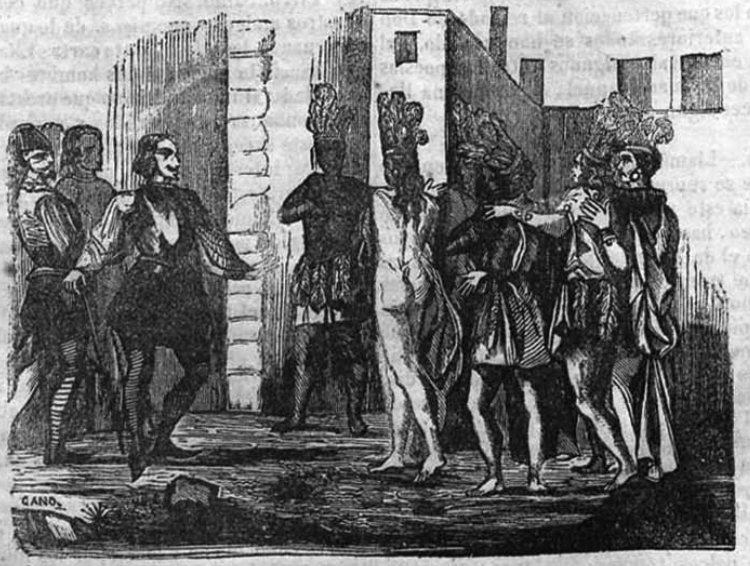

(Los Embajadores mejicanos se presentan á Hernan Cortés.) $+3$

Figura 2. Noticia sobre la actividad arqueológica de Ivo de la Cortina en la ciudad de Tarragona (Anónimo 1845). 
Era aquella una prensa decimonónica con plantillas modestas, pero bien estructuradas con un director, un consejo de redacción, un redactor jefe y periodistas de base, que recogía las noticias a través del correo postal. A pesar de la invención del teléfono, que informaba con mayor rapidez a finales de siglo, y hasta su generalización hacia la década de los veinte del posterior siglo xx, a las redacciones aún llegaban noticias en formato telegráfico. La escasa modernización, no alcanzar un mínimo estándar de modernidad y la baja demanda de lectores necesaria para mantenerlas en funcionamiento provocó que muchas rotativas tuvieran que cerrar.

\section{1. ¿Qué contaba la prensa?}

Del mismo modo que la prensa nacional publicaba noticias sobre los grandes hallazgos, a nivel local, la prensa dirigía sus plumas hacia lo que acontecía, si no en su municipio, en los de alrededor. Las secciones o espacios que recogen noticias sobre patrimonio varían mucho de una provincia a otra, siendo normalmente en las de Varia y Miscelánea donde se encuentren. Por ejemplo, en las gacetillas del Diario de Córdoba es donde se recogen la mayor parte de las noticias referidas a patrimonio arqueológico (Matías Cruz 2014, 275). Por lo general, se informa sobre descubrimientos, estudios arqueológicos, estado de conservación y restauración de monumentos, sobre la defensa del patrimonio, como cuando se demolió la Casa de la Moneda de la ciudad de Granada según publicó El Grito de Granada en el verano de 1843 (Rodríguez Domingo 2012, 302). También se produjeron en los periódicos denuncias del expolio de venta de piezas de Itálica, aireado por la prensa local en 1840 (Beltrán Fortes \& Rodríguez Hidalgo 2012, 45); o prensa local valenciana en 1853 sobre el estado de abandono de numerosos «restos antiguos» y la necesidad de crear un espacio para custodiarlos (Arasa Gil 2012, passim).

En 1844 se crearon las comisiones provinciales de monumentos histórico-artísticos dependientes de una comisión central en Madrid, inspirada en una ley francesa conocida como ley Guizot (Marín Hernández 2013, 326; Martínez Pino 2012, 15). La consecuencia principal de aquella actuación fue la aparición de los primeros museos provinciales de Bellas Artes que reunían colecciones de arqueología, pintura y escultura. A raíz de este hecho, la Ley de Instrucción Pública de 9 de septiembre de 1857 promulgó la creación de un museo en cada capital de provincia, si bien constituidos en su mayoría por fondos religiosos a raíz de las desamortizaciones. La política de las comisiones provinciales se mostró muy activa con sus nuevas encomiendas de supervisión de trabajos arqueológicos y de revisión del estado de conservación de los monumentos. Como ejemplo, la Comisión Provincial de Monumentos de Granada, a través de su secretario, José Giménez-Serrano, se valió de la prensa (diarios El Granadino y La Alhambra) para denunciar la destrucción del patrimonio andalusí y nazarí granadino (Salas Álvarez 2012, 73). Otro ejemplo más sobre aquellos trabajos son dos notas de prensa aparecidas en el Heraldo de Madrid. La primera, sobre una carta que el Conde de las Almenas dirigió al director del Diario de Burgos, en contestación a una comunicación de la Comisión de Burgos sobre las obras de restauración de la Cartuja de Miraflores. Y la segunda, anunciando que se había remitido a la Academia de San Fernando el expediente de declaración de Monumento Nacional de la Cartuja, para que emita dictamen (Almenas 1915, 3). Las noticias que en 1867 la prensa local emeritense presenta sobre el deterioro de monumentos en la ciudad, o las que en 1899 difunden los periódicos La República o El Noticiero Emeritense sobre la aparición de tres mosaicos romanos, o el mosaico de la calle Concordia en 1911 y otros eventos han sido recogidas con detalle por José Caballero Rodríguez (Caballero Rodríguez 2008, 47, 127, 236). Es anecdótico señalar que, ante la aparición de un sinfín de numerosos restos arqueológicos, en un breve espacio de tiempo, la 
prensa emeritense se afanará en componer sencillas coplillas sobre la acumulación ingente de "piedras» (Caballero Rodríguez 2008, 129).

Por su parte, en el semanario independiente Sóller de la localidad homónima Pedro Peyró informaba el sábado día 22 de mayo de 1897 de la celebración de una «Exposición Balear» con motivo de las fiestas de la Victoria, en la que da cuenta de que se ha instalado una sala de arqueología y ciencias geológicas, sin aclarar ni especificar qué piezas se exhibían. De lo escueto de la referencia arqueológica, vemos al menos que dicha actividad científica ya era objeto de exhibición e interés en localidades pequeñas como esta población mallorquina (Peyró 1897). En el mismo diario, el presbítero local José Rullán escribiría una larga crónica sobre la veracidad de la arqueología, y sobre las ciencias naturales, discurso que previamente había leído en la activa Sociedad Arqueológica Luliana de Palma de Mallorca. Era un discurso en el que reflexionaba sobre el desarrollo de la geología y la paleontología y la arqueología, ciencias a las que considera sus derivadas (Rullán y Mir 1898). En 1900 escribió un ensayo conjunto sobre la agricultura y la arqueología en el que los tres primeros capítulos los dedica a la arqueología con la misma disertación inicial que había publicado en el diario local que acabamos de citar (Rullán y Mir 1900). Eran tiempos en que el darwinismo estaba chocando con la religión y a muchos creyentes les estaba costando asumir las nuevas teorías de la evolución humana. A pesar de todo, Rullán y Mir siempre se mostró interesado en la protección del patrimonio como demuestra lo que escribió en el diario Sóller, el 16 de noviembre de 1907 sobre la necesidad de construir un museo que albergarse los restos hallados en un túnel (Rullán y Mir 1907).

Existieron en el siglo XIX periodistas interesados en arqueología y arqueólogos escribiendo en periódicos. Entre los primeros estuvo Estanislao de Koska Aguiló que figura como colaborador del Boletín de la Sociedad Arqueológica Luliana creada en 1885 (Ossorio y Bernard 1903, 4), Antonio Almagro Cárdenas, catedrático que colaboró con La Ilustración Española (ibid., 9), y, en tercer lugar, Ramón Arabla y Solanas, director de El Anuari, en el que se publicarían numerosos artículos sobre arqueología (ibid., 20). Por otra parte están Ángel del Arco, jefe del Museo de Tarragona que colaboró con la Revista de Archivos, Bibliotecas y Museos, el Boletín de la Academia Artístico-arqueológica de Barcelona, el Boletín de la Real Academia de la Historia y La Correspondencia de España (ibid., 22); José Brunet y Bellet que escribió en la Revista de la Asociación Artístico-arqueológica de Barcelona (ibid., 55); Francisco Caballero Infante, catedrático autor de numerosos escritos arqueológicos insertos en la Revista de Valencia y otros periódicos (ibid., 60); José Cascales y Muñoz, que escribía bajo seudónimo y perteneció a la Asociación de la Prensa de Madrid escribiendo en muchas publicaciones (ibid., 76); y, finalmente, Basilio Castellanos de Losada, director del Museo Arqueológico Nacional y periodista redactor de El Bibliotecario y del periódico militar el Guerrero de Mantua también usando seudónimos como «Santos Bueno del Castillo» y «el Tío Pilili» (ibíd., 78).

\section{2. ¿Quién practicaba la arqueología?}

En el siglo XIx la figura del arqueólogo de campo no existía, y el peso de esta labor recaía en la minoría culta bien formada compuesta por los eruditos locales, médicos, filólogos, periodistas, historiadores, aristócratas que hacían las veces de arqueólogos aficionados. A finales del siglo XVIII encontramos un claro antecedente a esta mezcla de profesiones encarnado por Isidoro Bosarte, secretario de la Academia de San Fernando, periodista, pero también erudito y arqueólogo (Saiz García 1983, 197). Ya en el XIX encontramos otros casos de aficionado no especialista como el matemático y arquitecto Eduardo Saavedra; el aristócrata aficionado Enrique Aguilera y Gamboa, marqués de Cerralbo, que después se institucionaliza (Barril \& Cerdeño 1997, 521-524); o Juan de Dios de la Rada «pomposo catedrático isabelino» que, aunque licenciado en derecho, se abrió hueco en el 
mundo académico de la arqueología (Pasamar Alzuria \& Peiró Martín 2002, 509-510). Ossorio incluye al marqués de Cerralbo en su libro sobre periodistas españoles informando que tomó parte en la redacción de El Fomento Literario de Madrid de 1863 a 1864, y colaboró con La Ilustración Católica desde 1877 hasta 1883 (Ossorio y Bernard 1903, 6). Entre los que provienen de otros saberes y desarrollan en nuestro país su carrera como arqueólogos estarán el pintor inglés afincado en Carmona (Sevilla), Jorge Bonsor, el ingeniero belga Luis Siret afincado en Herrerías (Almería), o el cónsul francés en Canarias, Sabin Berthelot (Díaz-Andreu et al. 2009, 25). Si bien es verdad que ya se está lejos de la imagen del anticuario con un gusto excelso por la ruina y lo que de ella se deriva, no es aún la disciplina moderna que hoy conocemos.

En el pasado la difusión de noticias sobre hallazgos arqueológicos recayó en su mayor parte en la prensa local y la prensa periódica nacional por el principio de proximidad (Gómez Alfeo 1997, 538), pero también en anuarios y boletines de las Reales Academias. En 1857, por el decreto Moyano, se suprime la Comisión Central dados los conflictos con las comisiones provinciales de monumentos, ordenando que sus funciones se repartan entre las reales academias (Historia y Bellas Artes), de ahí su labor difusora sobre noticias arqueológicas que señalamos en el texto. La Real Academia de Bellas Artes de San Fernando, que a veces informaba por fuentes secundarias, se hizo eco de noticias de la prensa extranjera. Como la escueta nota, de apenas cuatro líneas, sobre el «desenterramiento» de una cabeza de Minerva en Pérgamo (Anónimo 1881). A renglón seguido encontramos otra nota, de cinco líneas, en la que se menciona otra estatua de Minerva. Lo interesante es que la Academia tendría por disposición gubernamental un vaciado para el museo de «copias» [sic] que se estaba instalando en el Casón del Buen Retiro. Se trata del Museo de Reproducciones Artísticas. Pero también fuera de la capital, las instituciones dirigidas por instruidos locales - en las que gustaban de la divulgación científica, artística y literaria - se debatían los orígenes y ubicaciones de enclaves arqueológicos como Iliberri (ciudad romana ubicada debajo del actual Albaicín en Granada), siendo las encargadas de amenizar los, a veces enconados, debates historiográficos de aquellos ateneos (Sánchez Moreno 2018, 43). Todas las noticias publicadas contribuían a desgranar los hallazgos arqueológicos locales o las excavaciones en el exterior del país, acogiendo, en ambos casos, en sus columnas estudios de carácter informativo sin crítica alguna. A veces resultan meras noticias telegráficas o relaciones de acontecimientos arqueológicos, lo suficiente para el consumo cultural de la época. No había tanto público que consumiera periodismo gráfico al estilo europeo. Por su parte el Semanario Blanco y Negro (1891-1993) propició un periodismo gráfico más variado, basado la introducción de la moderna fotografía (Arranz Santos 2018, 7, 80), y la publicación periódica Museo Español de Antigüedades dirigida por Juan de Dios de la Rada y Delgado, también dedicó sus páginas a la arqueología.

\subsection{La divulgación en revistas}

Las revistas ilustradas surgen en la década de los años cuarenta del siglo xix con el perfeccionamiento de las artes gráficas, y en ellas tuvo el público un nuevo modo de acercarse a la arqueología. Surge un periodismo gráfico derivado del anterior, donde el grabado ocupa un lugar preeminente en este nuevo periodismo al ofrecer la imagen tanta información como el propio texto (Arranz Santos 2018, 75-76). Las revistas ilustradas sustituyeron a las anticuadas «pintorescas», convirtiéndose estas en lo moderno. Bajo este paraguas serán muy conocidas El Museo Universal absorbido por La Ilustración Española y Americana (1868-1921) (Díaz-Andreu et al. 2009, 23; Ten \& Celi Aragón 1996, 91-92, 110). Cabría esperar una amplia cobertura de noticias arqueológicas, pero sin embargo en más de cincuenta años apenas aparecieron 176 noticas en un periódico de tal magnitud (Arranz 
Santos 2018, 98). La suerte de este tipo de publicaciones acabaría a principios de los años veinte del siglo $\mathrm{xx}$, a lo que contribuiría el cambio técnico con el uso de tricromía y papel cuché del moderno semanario Blanco y Negro ya citado. Su irrupción renovó el formato de la divulgación, al dedicar espacio al patrimonio arqueológico y, al ser su marco nacional, tuvo gran predicamento puesto que llegaba a más audiencia que una tirada de periódico local (Arranz Santos 2018, 77-78).

A partir de los ańos treinta del siglo $\mathrm{xx}$, el escenario variará y se dividirán las publicaciones científicas. Comienzan a aparecer una serie de revistas para cada provincia y museo y surgirán un elenco de revistas científicas de corte divulgativo generalista, de lenguaje más asequible como Origen, o Destino que se publicó desde 1937 hasta 1980 (Figura 3). En Destino Luis Pericot y Miquel Tarradell publicarían sendas crónicas sobre Pere Bosch Gimpera y la Escuela de Arqueología de Barcelona (Pericot 1974a; Tarradell 1974). En la revista mensual África, operativa desde 1924 hasta 1978 y promovida, pese a su carácter popular, desde del Instituto de Estudios Africanos del CSIC (Fernández Moreno 2009, 149; García Collado 2018, 252), Luis Pericot escribió durante los años cincuenta y sesenta sobre sus estudios de prehistoria africana (Pericot 1954; 1955a; 1974a), y Martín Almagro Basch divulgó sobre las excavaciones en Nubia (Almagro Basch 1966). Por otra parte en la Revista de Gerona Almagro Basch difundió las excavaciones de Ampurias (Almagro Basch 1955; Almagro Basch \& Palol Salellas 1962) y Pericot colaboró profusamente durante veinte años (Pericot 1955b; 1959; 1961; 1965; 1973; 1974b; 1975; 1976).
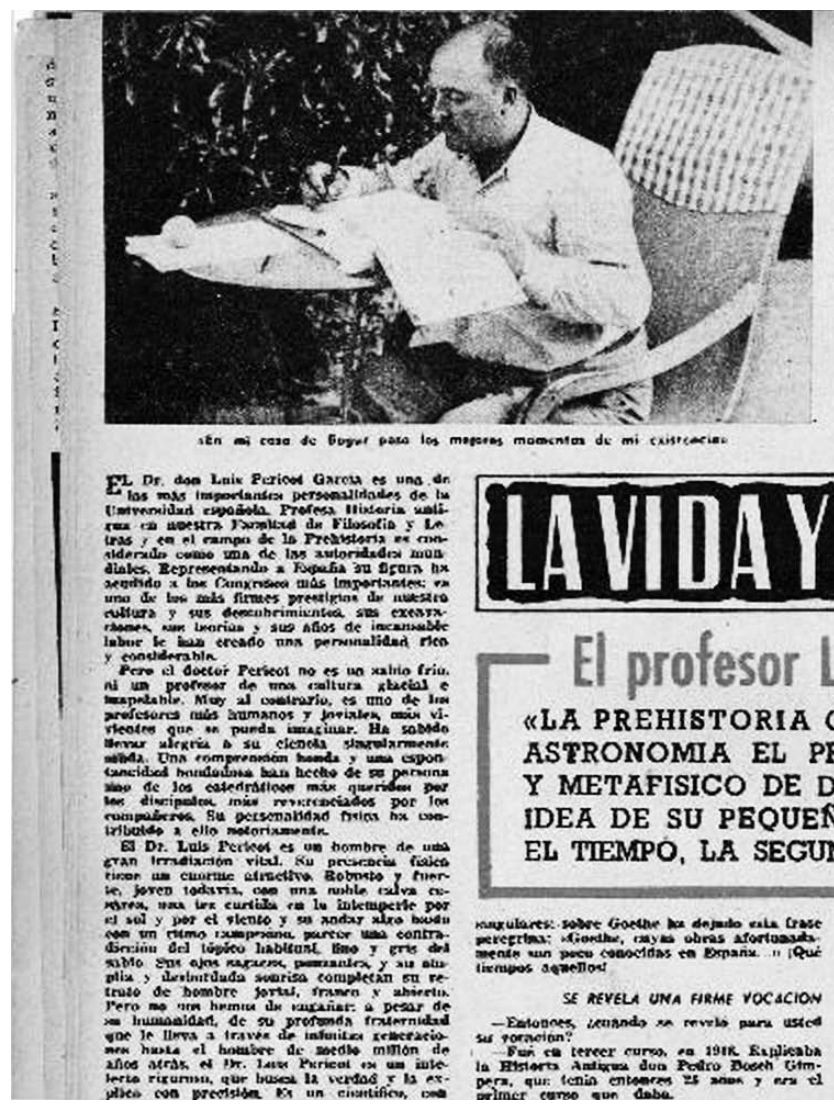
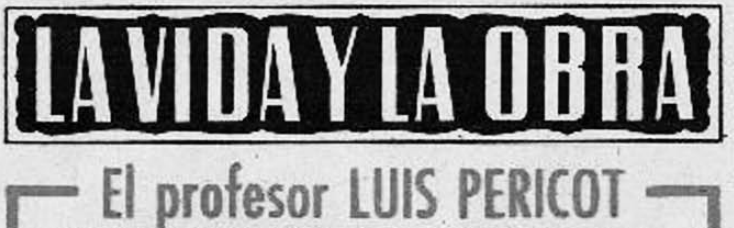

«LA PREHISTORIA COMPARTE CON LA ASTRONOMIA EL PRIVILEGIO POETICO Y METAFISICO DE DAR AL HOMBRE UNA IDEA DE SU PEQUENEZ; LA PRIMERA EN EL TIEMPO, LA SEGUNDA EN EL ESPACION

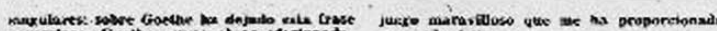

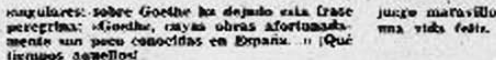
SE REVELA UNA FIRME VOCACIOY

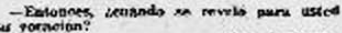

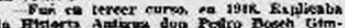

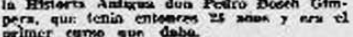
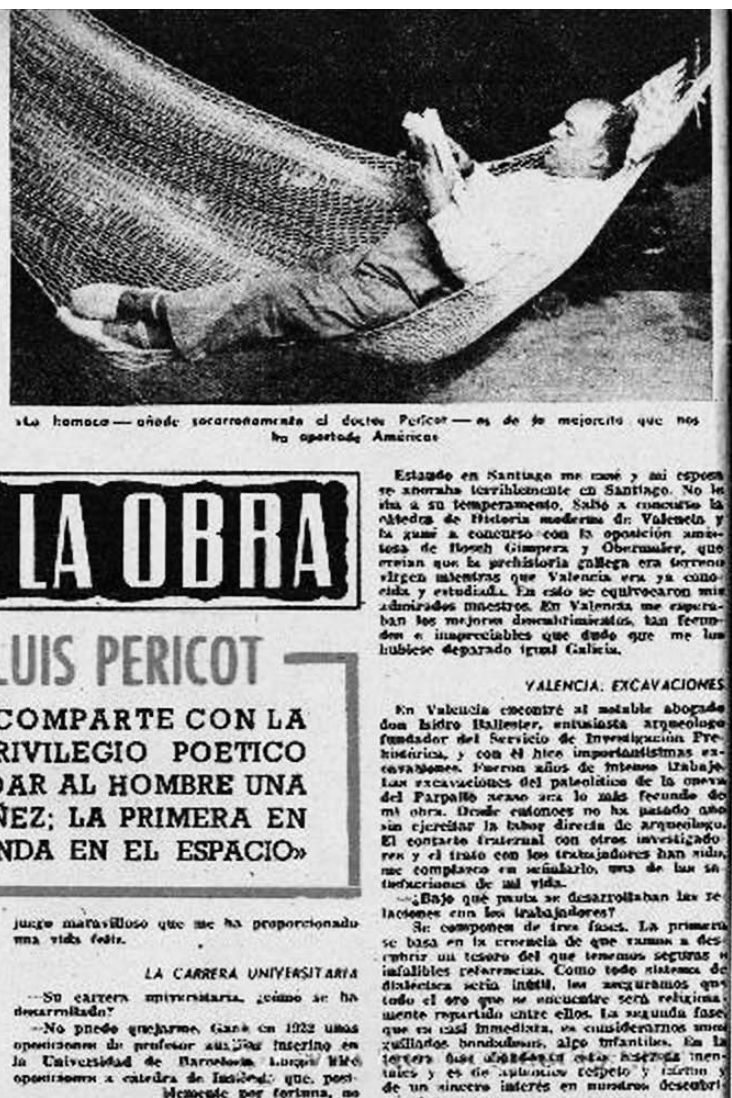

Figura 3. Recorte de la revista Destino en la que se entrevista al prehistoriador Luis Pericot. 


\section{El SigLO XX}

\subsection{Modernización y pluralidad del formato}

Un dato que muestra el interés por la publicación en papel es que entre 1885-1891 se pasó de 83 a 226 cabeceras (Matías Cruz 2014, 277). Tras un vistazo a los diferentes periódicos se revela el interés que el patrimonio arqueológico despierta y los interrogantes que suscita. En los primeros años del siglo xx la incesante actividad arqueológica provocó un goteo de noticias. Es el siglo del despliegue mediático sobre los descubrimientos de la tumba de Tutankhamon en 1922. Howard Carter visitó España en 1924 para dar a conocer los hallazgos impartiendo varias conferencias. El 24 de noviembre en la Residencia de Estudiantes, después en el teatro Fontalba. Volvió en el año 1928 pronunciando de nuevo conferencias en la Residencia de Estudiantes y el teatro La Princesa en Madrid (García Rodríguez 1997, 534-535; Seco Álvarez \& Martínez Babón 2017). La exitosa visita daría lugar a la aparición de sucesivos reportajes en la revista ilustrada La Esfera durante los meses de febrero, marzo, abril y mayo de ese mismo año (La Esfera 1924). Se hizo eco toda la prensa nacional, entre otros El Heraldo de Madrid, El Liberal, El Sol, La Nación, y ABC.

En 1905, la Sociedad Española de Excursiones de Madrid realizará una visita a la ciudad de Mérida en que la presencia del arquitecto y académico Vicente Lampérez sirvió de polo de atracción a las excavaciones del teatro romano por el arqueólogo madrileño José Ramón Mélida. Acudirán atraídos por lo allí descubierto tras la lectura de las noticias, célebres como Adolf Schulten y José Catalina García López (Caballero Rodríguez 2008, 167-169). El turismo incipiente, reservado a unos pocos, y el envío de tarjetas postales ilustradas de estos cultivados asistentes tras sus visitas arqueológicas sirvieron también de difusión del patrimonio. Su lectura resulta útil para el análisis arqueológico, máxime al tratarse de opiniones directas de los propios arqueólogos, resultando una fuente de información primaria fundamental.

Nos detenemos en la figura de Mélida, ávido escritor que enviaba sin cesar noticias arqueológicas a la prensa (Gómez Alfeo 1997, 440). Colaboró de manera casi diaria con periódicos como El Correo de Madrid y los sorianos El Avisador Numantino, Noticiero de Soria, y puntualmente en $A B C$, La Provincia y La Voz de Soria. Al respecto, Díaz-Andreu y Casado Rigalt señalan que el archivo del Museo Arqueológico Nacional custodia unas cuartillas en las que fue guardando recortes de periódico con sus artículos de la serie Numantia sobre el yacimiento celtibérico soriano (Casado Rigalt 2006, 239; Díaz-Andreu 2004, LXXIX-LXXV). Estos recortes de periódico han tomado sentido gracias al análisis detallado y sistemático que realiza Gómez-Barrera (2008) sobre el contenido de los artículos de Mélida. Tan solo decir que para el manejo de toda la información que estudia sobre el período 1906-1934, agrupa el contenido de los artículos de la siguiente manera: artículos firmados por Mélida de difusión nacional que se refieren a Numancia y noticias más locales que atañen a monumentos de la provincia como el monasterio de San Juan de Duero o la iglesia de Santo Domingo, ambos en Soria; artículos de documentación periodística en torno a él, que reseñan su actividad arqueológica por toda la provincia; y, por último, artículos de opinión en la prensa soriana en los que citan a Mélida.

En 1960 nos parece interesante detenernos en el seguimiento periodístico de los trabajos arqueológicos en Nubia. La UNESCO — como parte de la política exterior de la propia organizaciónalentaba siempre a las organizaciones de prensa, cine, radio y televisión mundiales a difundir los acontecimientos culturales y en este caso también se manifestó en favor del seguimiento de la campaña. Así lo hacía constar en una circular informativa del año 1961 UNESCO/CUA/106, 1961, lo que resultaría en la publicación de numerosas noticias, reportajes fotográficos y artículos como el ar- 
tículo de Ritchie Calder titulado Abu Simbel Now or Never (Calder 1961, 4). Se dará la feliz confluencia de que, por parte española, enviarán como cronista al dibujante y periodista al profesor Pedro Lozano Bartolozzi que hará las veces de arqueólogo. Lozano fue admitido como un miembro más de la expedición en la campaña del año 1963-1964 de Masmas en la Nubia egipcia (Monreal Agustí 1964). Fue el primer corresponsal oficial destacado sobre el terreno, estrenándose con sus crónicas para el Diario de Navarra y enviando sus artículos a la agencia Europa Press (Figura 4). Que solo fuese Lozano no indica que con anterioridad no se hubiese cubierto la Campaña de Salvamento de Nubia, pero eran noticias de agencias como Pyresa, EFE, o de periodistas que resumían los acontecimientos como ERO (seudónimo de Álvaro Ruibal), Joaquín Arrarás, Manuel Menéndez-Chacón, y corresponsales como Cristóbal Tamayo (seudónimo de Joaquín Navarro Cristóbal de La Vanguardia) y Enrique Meneses entre otros. El impacto social de la relación arqueología-periodismo fue la difusión exhaustiva de la campaña, ya que se informó hasta la saciedad de los pasos y aconteceres de los arqueólogos en el campo, como muestran las noticias de prensa que aparecían en los países implicados, y en los propios canales de la UNESCO como la revista The Unesco Courier.

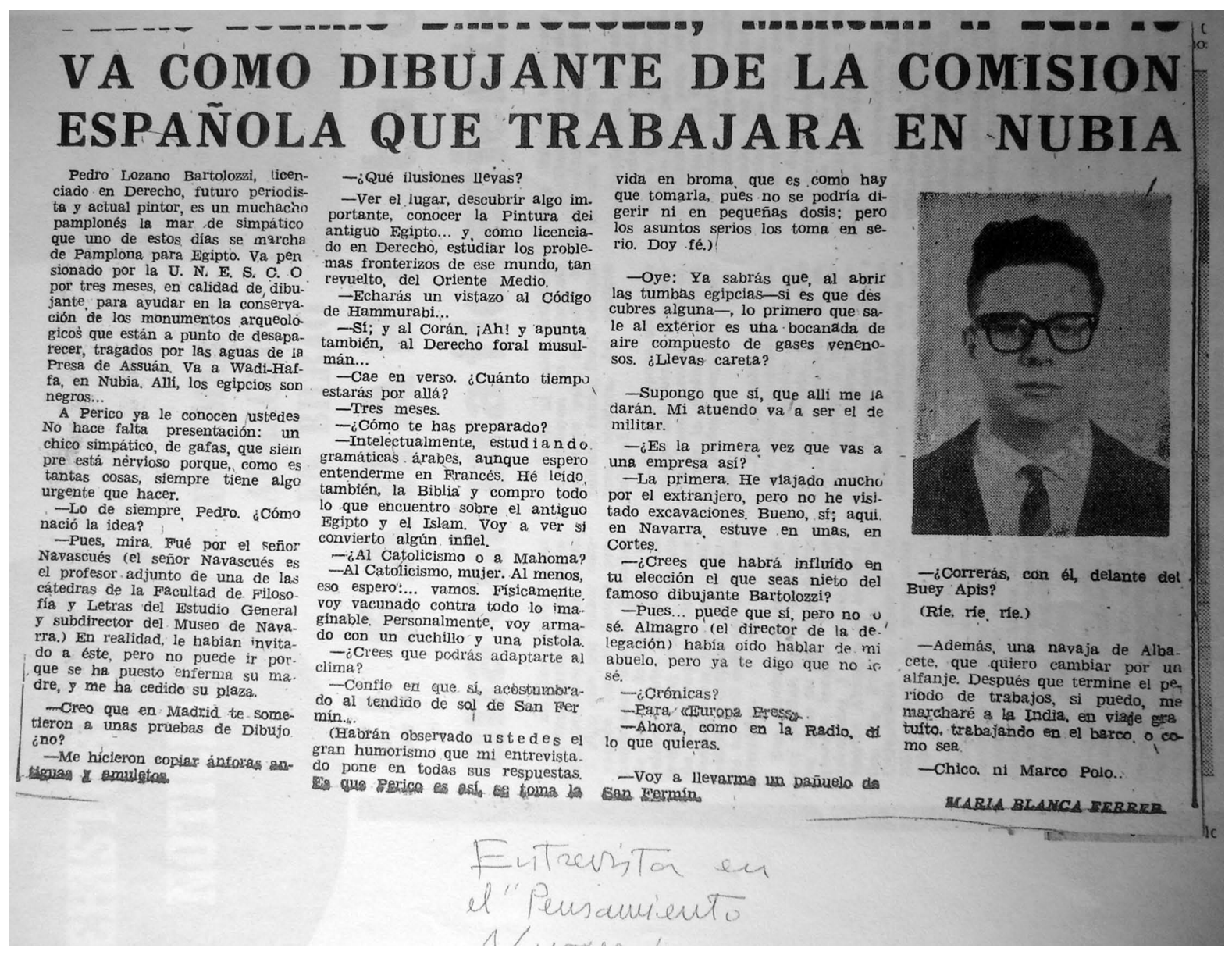

Figura 4. Pedro Lozano Bartolozzi entrevistado, en 1964, por María Blanca Ferrer para el periódico Pensamiento Navarro antes de partir hacia Nubia (Recorte de prensa proporcionado directamente por el profesor Lozano Bartolozzi, sin que hayamos podido identificar el número en el que se le realiza la entrevista). 


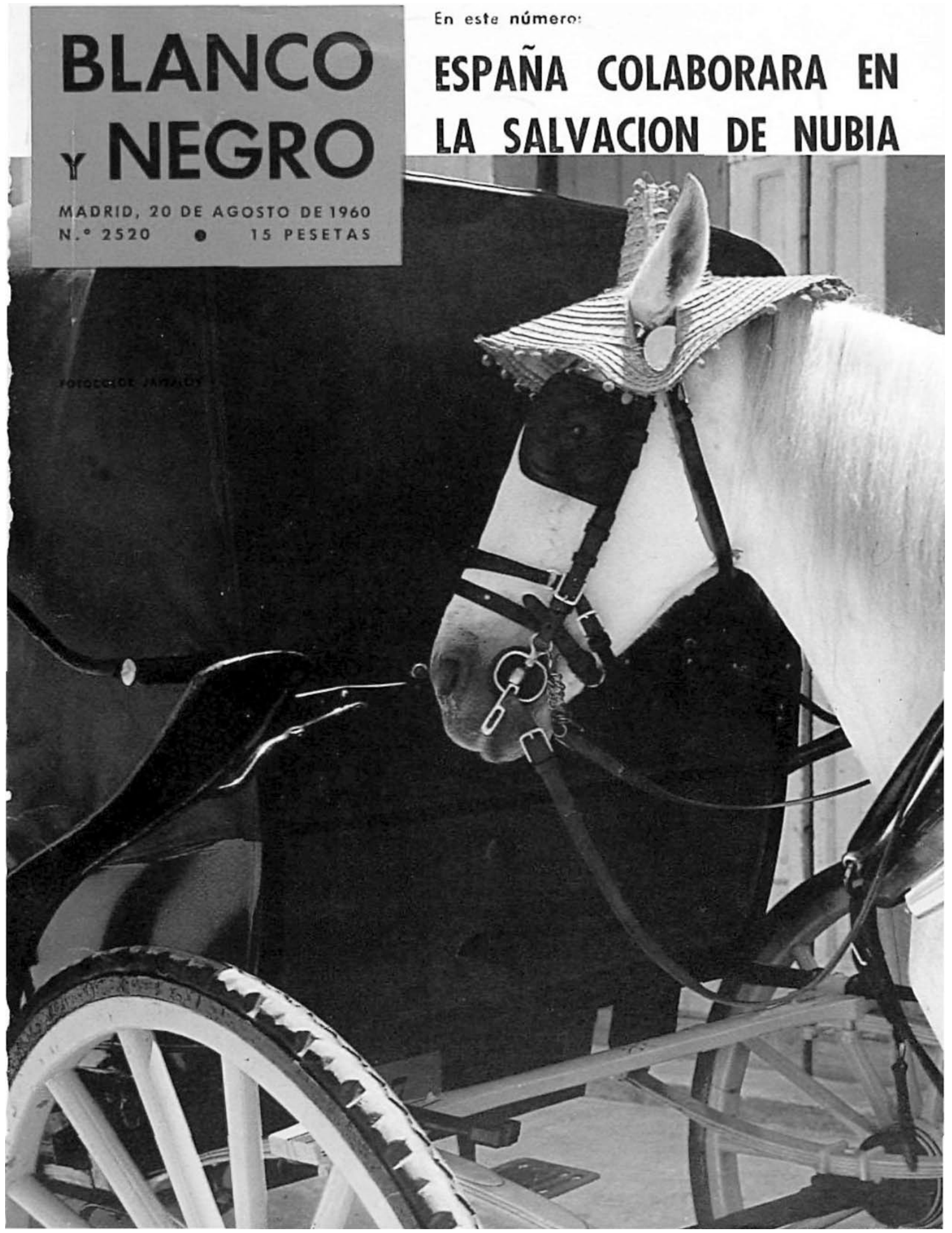

Figura 5. Portada del semanario Blanco y Negro que contenía un reportaje especial dedicado a la Campaña de Nubia con artículos de Menéndez-Chacón 1960 y Meneses 1960. 
En los años ochenta, la prensa publicó un caso antiguo de falsificación difundido por El Sol, el de la tablilla de Glozel sobre el que había comentado Bosch Gimpera en su momento (García Rodríguez 1997, 531). También se debatió en 1982 un hallazgo sobre el que se presentaron dudas: el llamado Hombre de Orce. La tesis doctoral de Victoria Moreno Lara (2014) dedica un espacio transversal a la polémica de Orce, dentro del tratamiento general del trabajo sobre Atapuerca en la prensa; y la de Miquel Carandell Baruzzi se dedica por entero a Orce (Carandell 2015). Se aprecia en ambos trabajos la diferente comunicación científica y mediática que recibieron sendos yacimientos. La presentación pública del fragmento craneal en cuestión se realizó en una multitudinaria conferencia de prensa que atrajo a diferentes medios de comunicación, a la que no faltaron las autoridades políticas locales granadinas y catalanas, junto con los docentes universitarios que la arroparon (Carandell 2015, 17, 128; Moreno Lara 2014, 317-318), dispensándole al hallazgo una divulgación mediática anterior a la académica, lo que contribuyó a aumentar la desconfianza hacia la veracidad de la datación del resto óseo (Moreno Lara 2014, 319, 325). La atribución posterior de los restos a un asno y no a un homínido ocupó, como nunca antes había ocurrido en época democrática, la portada del periódico El País. Conocemos solo otros dos casos más del período que analizamos sobre noticias arqueológicas que abren portadas. La del semanario Blanco y Negro (Figura 5) donde se anuncia la implicación española en Nubia con un reportaje del periodista Enrique Meneses (1960) y una crónica de Manuel MenéndezChacón (1960); y la portada del Diario de Barcelona el día 16 de abril de 1964 (Zurinaga Fernández-Toribio 2009b, 52).

\subsection{Gremios y parcelas. Relaciones entre periodismo y arqueología}

Inicialmente se practicó una labor informativa por parte de periodistas-arqueólogos, médicosarqueólogos, poetas-arqueólogos, eruditos-arqueólogos, aristócratas-arqueólogos, hasta que se produjo la profesionalización definitiva de arqueólogos y periodistas en el siglo xx, produciéndose unas relaciones recíprocas que existen desde hace bastante tiempo (Ascherson 2004). Por estas, según nos comenta Ascherson, los arqueólogos se han ayudado de la prensa para difundir sus investigaciones, aparte de la divulgación arqueológica que la propia prensa realice en sus diarios. Aparte de la prensa, este autor analiza los estereotipos que han representado a los arqueólogos como exploradores, recolectores de objetos, y anticuarios pasando por la figura del profesor trastornado, apasionado de la disciplina (Ascherson 2004, 145, 153), estereotipos que han servido de alegato en defensa de la asignatura de arqueología, para que no desapareciera del currículo educativo británico (Thornton 2018, 1-2). Sin embargo, estos clichés tienen más que ver con el colonialismo que con la arqueología postcolonial actual.

La aproximación a la prensa finisecular nos ha dejado ver la primera de las relaciones mantenidas entre ambos campos, unos académicos bien instruidos, pertenecientes a sociedades arqueológicas, sociedades de amigos del país, sociedades de excursionistas, círculos literarios etc., que participan desde la propia redacción del periódico que dirigen, o por medio de colaboraciones mantenidas a lo largo del tiempo, o con colaboraciones de carácter puntual. Llama la atención la multitud de personajes que escriben sobre arqueología perteneciendo a la Iglesia, o siendo miembros de las Reales Academias, directores de museos, o catedráticos de Universidad. Paralelamente existe una sociedad erudita con inquietudes intelectuales compuesta por médicos como Enrique Fajarnés i Tur que actúan como periodistas y escriben en revistas arqueológicas como el ya citado Boletín de la Sociedad Arqueológica Luliana (Ossorio y Bernard 1903, 124), o poetas como Bartolomé Ferrá y Perelló, director del Museo Arqueológico Luliano y colaborador del diario La Última 
hora de Palma (Ossorio y Bernard 1903, 136). Ossorio, al incluirlos a todos bajo el mismo denominador común de periodistas, enmascara la realidad ya que un doctor en letras o un miembro de una Real Academia cuando escribe sus trabajos para un periódico o, en el siglo xx, cuando participa en una tertulia radiofónica, conferencia, etc., no es un periodista. Es como si a Martín Almagro Basch por los artículos de divulgación que preparó para revistas como Africa, Atlántida, Arte y Hogar, Vida Escolar, Revista de Enseñanza Media, Arbor, Las Ciencias, Villa de Madrid, o Aula de Cultura, o las crónicas que escribió para periódicos como El Alcázar, Arriba, etc., o por las múltiples noticias de prensa en las que aparece, se le tildara de reportero o corresponsal. Así Thornton analiza el papel que desempeñaron los arqueólogos y arqueólogas británicas desde 1870 a 1970 divulgando arqueología para el público no experto, comercializando sus conocimientos y haciendo visibles públicamente sus excavaciones a través de los periódicos entre otros medios. En un proceso consciente de modelar su trabajo para la comprensión general del público, para lo que no dudaron en servirse de la radio, la fotografía o la prensa, hallaron en los periódicos una valiosa plataforma para promocionar la disciplina y compartir sus conocimientos (Thornton 2018, 75-76), lo cual en nuestra opinión no les convierte en periodistas.

\section{RefleXiones FinAlES}

Antes la prensa escrita, como hoy los medios de comunicación en general — sean cuales sean sus formatos, periódicos, revista, suplementos, suplementos especiales, medios digitales y redes sociales-, informaba de manera sesgada y dirigida. Desde el momento que en la redacción se decide qué se publica y qué no, se está produciendo un sesgo informativo. Divulgar arqueología no es ajeno a esta práctica; la cultura en general es fácilmente manipulable y los intereses políticos se suelen cruzar en su camino. La academia ha de luchar contra estas intromisiones, y el periodismo ha de informar con rigor e imparcialidad. A pesar de las críticas por el tratamiento que la arqueología reciba en los medios, sin duda, su presencia ayuda a la difusión del patrimonio arqueológico, despertando el interés por su protección, conservación, estudio y de nuevo difusión de estos estudios. En este carrusel de investigación y divulgación, la prensa y la disciplina arqueológica van de la mano: unas veces los periodistas conocen de primera mano los contextos, ya que pertenecen a esa ciudad y han seguido de cerca los trabajos, por tanto, sus crónicas no es que estén más elaboradas, es que son más precisas; otras publican lo que el científico les cuenta.

Por el estudio realizado, hemos visto que en el siglo XIx los arqueólogos ejercían de "guías turísticos» de las autoridades interesadas en acudir a un determinado yacimiento para ver los trabajos de excavación, restauración o rehabilitación en curso (Morán Sánchez 2013, 2190, 2196), recayendo la labor de difusión directamente en los arqueólogos al emitir ellos sus propias crónicas para que la prensa las publicara, sin menoscabo de cuantas publicaran los periodistas locales o regionales. Según las excavaciones se van haciendo más frecuentes, la prensa se va interesando más en la arqueología. El nuevo interés lleva a la publicación de extensos reportajes, no quedándose solo en la breve noticia sobre un hallazgo puntual. La difusión contribuía también a las relaciones internacionales entre colegas, como cuando Jorge Bonsor viaja a Mérida a ver los trabajos de José Ramón Mélida, lo hace gracias a lo que ha leído en la prensa, comenzando tras la visita una relación de amistad profesional con el arqueólogo español (Caballero Rodríguez 2008, 250; Morán Sánchez 2013). Esto mismo está constatado en la Campaña de Nubia y las relaciones que Martín Almagro Basch trabó con los reputados nubiólogos y egiptólogos de la época. La fotografía en una especie de inicial «fotoperiodismo» comienza a acompañar la noticia arqueológica con imágenes ha- 
cia 1897, no obstante, la fotografía arqueológica ya se usaba desde 1860 (González Reyero 2006, 181, 197). Muchas veces son los propios arqueólogos «modernos» los que las realizan y se envían a la prensa diaria, a revistas como Por esos mundos, Blanco y Negro, La Esfera, Mundo Gráfico o Nuevo Mundo, o a las Reales Academias para publicarse en las memorias correspondientes. Son fotografías con buenos encuadres que no ocultan el momento preciso. Mélida se mostró un entusiasta de esta nueva técnica a la que desde el principio consideró esencial para documentar sus trabajos, proveyéndose de un fotógrafo que realizaba las tomas y las enviaba a periódicos tales como $\mathrm{ABC}$ (Caballero Rodríguez 2008, 212-214, 221).

Destacan dos figuras coincidentes en cierto modo, a pesar de su lejanía en el tiempo. Nos referimos a José Ramón Mélida, a caballo entre el siglo xIx y el xx, y Martín Almagro Basch, en el tercer cuarto del siglo xx. Ambos supieron ver el poder de la prensa y el alcance de la difusión de sus trabajos a través de este medio. Por eso, lejos de replegarse en su labor de estudiosos infatigables se arrimaron a la sombra de este llamado cuarto poder. Ambos supieron ver la rentabilidad de figurar entre las páginas que los periódicos les ofrecían. Sabedores de que los hallazgos sufragados con dinero público debían revertir a la sociedad, se afanaron en difundir sus excavaciones con los medios modernos de entonces, como la fotografía arqueológica en el caso de Mélida, si bien, en este uso, Juan Cabré fue un maestro (Blánquez Pérez \& Rodríguez Nuere 2004); todo ello en favor de inculcar la preservación (conservación y restauración) del patrimonio monumental, histórico, artístico y arqueológico, hoy patrimonio cultural. Sería muy interesante analizar el público que consumía toda esta masa informativa. Realizando a vuela pluma un escueto análisis de la estructura social, podríamos decir que serían las clases aristocráticas y las burguesas adineradas las que tuvieran acceso a la prensa. Eran las que tenían estudios y las que visitaban yacimientos y museos.

Adentrándonos ya en el siglo xx, la prensa tomará forma, y surgirán nuevos públicos como la prensa dirigida a la clase obrera de los años veinte y treinta, y se abrirán otros nichos de mercado, como la prensa dirigida al sector femenino en los años cincuenta y sesenta. A partir de los años cincuenta del siglo xx, el consumo de prensa se afianza, y hacia los años sesenta se generaliza y la clase media accede a ella. Se consume prensa afín al régimen franquista hasta que la llegada de la ley de prensa de 1966 va abriendo la mano de la censura y permite la apertura de nuevos periódicos. En la actualidad y parafraseando a Meneses, los arqueólogos son los anfitriones de los periodistas (Meneses Fernández 2011, 370). Los medios deben acompañar a los arqueólogos en la tarea, porque siempre habrá una historia — a nivel local_ para contar, que pueda interesar al público (Stone 1989, 203).

El balance general se sustancia en el marcado interés del mundo periodístico en la disciplina arqueológica y todo lo que le rodea, que puede rastrearse desde hace centurias, tanto en la prensa de provincias como en la prensa nacional, constatándose que nunca ha existido una relación interdisciplinar sensu stricto entre ambas - puesto que la interacción ha ocurrido sin que el periodismo teorice sobre los postulados científicos arqueológicos_-, aunque sea la prensa la que genere estados de opinión sobre los trabajos arqueológicos que presente, ya que es el científico quien construye el conocimiento sobre la arqueología que luego el periodista se encarga de difundir. A lo sumo, se podría hablar de una interacción bi-disciplinar, al ser el periodismo un puente entre la arqueología y la sociedad. 


\section{BibLiografíA}

Almagro Basch, M., 1955, "Gerona en la historia de las excavaciones de Ampurias», Revista de Gerona I, 75-82.

Almagro Basch, M., 1966, «La participación de España en la Campaña de Nubia», África 300, 10-15.

Almagro Basch, M., \& P. D. Palol Salellas, 1962, "Los restos arqueológicos paleocristianos y altomedievales de Ampurias», Revista de Gerona XX, 27-41.

Almenas, C. D. L., 1915, «La Cartuja de Miraflores. Una tempestad en un vaso de agua. (Arte y Artistas)», Heraldo de Madrid 27 (27 septiembre), 3.

Álvarez-Sanchís, J., \& G. Ruiz Zapatero, 1998, «España y los españoles hace dos mil años según el bachillerato franquista (período 1936-1953)», Iberia: Revista de la Antigüedad 1, 37-52.

Anónimo, 1807, «Antigüedades», Minerva o El Revisor general XI (6 de febrero. Sección Antigüedades), 81, 225.

Anónimo, 1845, «Antigüedades», Semanario Pintoresco Español 40, 320.

Anónimo, 1881, «Noticias», Boletín de la Real Academia de Bellas Artes de San Fernando 1 (1), 30.

Anónimo, 1924, "El rico tesoro arqueológico del Valle de los Reyes», La Esfera Madrid, 23 de febrero 529, 3-4.

Anónimo, 1924, «Los tesoros arqueológicos de Luxor», La Esfera Madrid, 1 de marzo 530, 16.

Anónimo, 1924, "El maravilloso sepulcro del "Hijo del sol”", La Esfera Madrid, 1 de marzo 530, 17.

Anónimo, 1924, "El trono de Tutankhamen: su significado mágico», La Esfera Madrid, 8 de marzo 531, 23.

Anónimo, 1924, «El carro de ceremonia del faraón», La Esfera Madrid, 15 de marzo 532, 21-22.

Anónimo, 1924, "Apertura oficial de la tumba de Tutankhamen», La Esfera Madrid, 17 de mayo 541, 19.

Araza Gil, F., 2012, "La arqueología valenciana tras la desamortización», en: C. Papí Rodes, G. Mora, M. Ayarzagüena (eds.), El patrimonio arqueológico en España en el siglo XIX. El impacto de las desamortizaciones, Madrid: Ministerio de Educación, Cultura y Deporte, 83-102.

Arranz Santos, R., 2018, «La Arqueología en la prensa nacional: el caso de La Ilustración Española y Americana», en: S. España-Chamorro, R. Arranz Santos, A. Romero Molero (eds.), Colecciones, arqueólogos, instituciones y yacimientos en la España de los siglos XVIII al XX. [Access Archaeology], Oxford: Archaeopress: 75-109.

Ascherson, N., 2004, «Archaeology and the British media», en: N. Merriman (ed.), Public Archaeology, London and New York: Routledge, 145-158.

Barril, M., \& M. L. Cerdeño, 1997, «El Marqués de Cerralbo y su aportación a la arqueología española», en: G. Mora, M. Díaz-Andreu (eds.), La cristalización del pasado. Génesis y desarrollo del marco institucional de la arqueología en España. Madrid, Málaga: Ministerio de Cultura, Universidad de Málaga, 515-528.

Beltrán Fortes, J., \& J. M. Rodríguez Hidalgo, 2012, "Las primeras excavaciones oficiales en Itálica: Los trabajos de Ivo de la Cortina en el año 1839», Revista Itálica 2, 29-51.

Belzoni, G. B., 1818, «Noticias Literarias. Sobre las antigüedades egipcias», Minerva o El Revisor general LI (18 de junio), 211.

Belzoni, G. B., 1820, Narrative of the Operations and Recent Discoveries within the Pyramids, Temples, Tombs, and Excavations in Egypt and Nubia, London: J. Murray.

Blánquez Pérez, J., \& B. Rodríguez Nuere (eds.), 2004, El arqueólogo Juan Cabré (1882-1947). La fotografía como técnica documental, Madrid: Instituto de Patrimonio Histórico Español, Universidad Autónoma de Madrid, Museo de San Isidro.

Caballero Rodríguez, J., 2008, Maximiliano Macias y su tiempo (1867-1934). Historia intima de las grandes excavaciones en Mérida, Mérida: Artes Gráficas Rejas.

Carandell, M., 2015, Orce Man. A Public Controversy in Spanish Human Origins Research (1982-2007), Barcelona: Universitat Autònoma de Barcelona. Online.

Casado Rigalt, D., 2006, José Ramón Mélida y la arqueología española, Madrid: Real Academia de la Historia. 
DíAz-Andreu, M., 2004, «Mélida: génesis, pensamiento y obra de un maestro», en: J. R. Mélida (ed.), $A r-$ queología española. [Clásicos de la historiografía española], Pamplona: Urgoiti, I-CXCIX.

Díaz-Andreu, M., \& G. Mora, 1995, «Arqueología y política: el desarrollo de la arqueología española en su contexto histórico", Trabajos de Prehistoria 52 (1), 25-38.

Díaz-Andreu, M., G. Mora \& J. Cortadella, 2009, «Introducción», en: M. Díaz-Andreu, G. Mora, J. Cortadella (eds.), Diccionario Histórico de la Arqueología en España (siglos XV-XX), Madrid: Marcial Pons: $13-57$.

Fernández Moreno, N., 2009, Antropología y colonialismo de África subsahariana. Textos etnográficos, Madrid: Editorial Universitaria Ramón Areces.

García Collado, M. Á., 2018, «Viajeros y arabistas a doble paso: Marruecos colonial y el legendario Joaquín Gatell», Revista de Dialectología y Tradiciones Populares LXXIII (1), 249-265.

García Rodríguez, F., 1997, «Arqueólogos, historiadores, escritores y periodistas», en: G. Mora, M. DíazAndreu (eds.), La cristalización del pasado. Génesis y desarrollo del marco institucional de la arqueología en España, Madrid, Málaga: Ministerio de Cultura, Universidad de Málaga, 529-536.

Gómez-Barrera, J. A., 2008, «Aportaciones a la bio-bibliografía de José Ramón Mélida Alinari desde la prensa soriana de su tiempo (1906-1934)», Sautuola XIV, 439-464.

Gómez Alfeo, M. V., 1997, "Visión de la arqueología en la prensa española en el primer tercio de siglo», en: G. Mora, M. Díaz-Andreu (eds.), La cristalización del pasado. Génesis y desarrollo del marco institucional de la arqueología en España, Madrid, Málaga: Ministerio de Cultura, Universidad de Málaga, 537-545.

GonzÁlez ReYero, S., 2006, "La fotografía en la historia de la arqueología española (1860-1960): Una aproximación a la aplicación y usos de la imagen en el discurso histórico", Archivo español de arqueología $193,155-176$.

Harry, M., 1924, «El doloroso enigma de Tut-Ankh-Amon», La Esfera Madrid, 22 de marzo 533, 27-28.

Harry, M., 1924, «La vida de los faraones revelada por sus reliquias», La Esfera Madrid, 12 de abril 536, $12-13$.

Hernández Márquez, B., 2001, El papel de la prensa en las etapas de transición a la democracia. (El caso español), Madrid: Tesis Doctoral. Universidad Complutense de Madrid.

Marín Hernández, C., 2013, «Las comisiones de monumentos en la institucionalización de la Arqueología española contemporánea (siglos XIX-Xx)», Arqueogazte 3, 323-339.

Martínez Pino, J., 2012, «La gestión del patrimonio histórico artístico en el siglo XIx. Fuentes para su documentación. Tejuelo", Revista de ANABAD-MURCIA 12, 10-21.

Matías Cruz, J., 2014, «Visión y transmisión de la arqueología y el patrimonio histórico a través de la prensa cordobesa: Diario de Córdoba (1885-1891)», Revista Anagramas 1, 273-289.

Menéndez-Chacón, M., 1960, «Una comisión española asume la tarea de salvar algunas de las zonas arqueológicas amenazadas de inundación", Blanco y Negro 20 de agosto, 34-36.

Meneses, E., 1960, «El tesoro arqueológico de Nubia será sepultado bajo sesenta metros de agua», Blanco y Negro 20 de agosto, 30-33.

Meneses Fernández, D., 2011, «Periodismo, medias y patrimonio: de la curiosidad arqueológica y paleontológica a la ciencia y al desarrollo zonal. Universidad de La Laguna (Tenerife)», Estudios sobre el mensaje periodístico 17 (2), 365-381.

Monreal Agustí, L., 1964, Tesoros de Nubia: expedición arqueológica a Egipto y Sudán, Barcelona: Juventud.

Morán SÁNChez, C. J., 2013, «El reflejo de la prensa nacional sobre la recuperación del teatro romano», en: J. Jiménez Ávila, M. Bustamante Álvarez, M. García Cabezas (eds.), Actas del VI Encuentro de Arqueología del Suroeste Peninsular. Villafranca de los Barros, 2013, Villafranca de los Barros: Ayuntamiento de Villafranca de los Barros, 2180-2232.

Moreno Lara, V., 2014, Atapuerca: Arqueología y evolución humana en la prensa. Madrid: PhD Thesis, Universidad Complutense de Madrid.

Ossorio y Bernard, M., 1903, Ensayo de un catálogo de periodistas españoles del siglo XIX, Madrid: Imprenta y litografía de J. Palacios. 
Pasamar Alzuria, G., \& I. Peiró Martín, 2002, Diccionario Akal de historiadores españoles contemporáneos (1840-1980), Madrid: Akal.

Penedo Cobo, E., \& C. J. Caballero Casado, 2009, «La cornisa de San Francisco El Grande y Seminario Conciliar: patrimonio, sociedad y paisaje urbano. La politización del patrimonio histórico», VI jornadas de Patrimonio Arqueológico en la Comunidad de Madrid. Madrid: Comunidad de Madrid, 427-441.

Pericot, L., 1954, «El problema del paso del Estrecho de Gibraltar en el Paleolítico Superior», África (Madrid) XI, 448-450.

Pericot, L., 1955a, «El III Congreso Panafricano de Prehistoria», África (Madrid) XII, 541-543 (= Zephyrus VI, 1955, 305-307).

Pericot, L., 1955b, «La arqueología en la provincia de Gerona», Revista de Gerona I, 63-67.

Pericot, L., 1959, «La primera descripción de la Costa Brava», Revista de Gerona V, 41-44.

Pericot, L., 1961, «Ullastret. Impresiones y recuerdos», Revista de Gerona VII, 13-16.

Pericot, L., 1965, «El destino de la antigua Rosas», Revista de Gerona XI, 7-12.

Pericot, L., 1973, «Mi Fontana de Oro, recuerdos de adolescencia», Revista de Gerona XIX, 48-50.

Pericot, L., 1974a, «Algunos de mis recuerdos de Bosch Gimpera», Destino 1934 (26 octubre), 9-10.

Pericot, L., 1974b, «Miquel Oliva, recuerdos de una amistad», Revista de Gerona XX, 37-40.

Pericot, L., 1975, «Els meus records de Prudenci Bertrana», Revista de Gerona XXI, 1975, 38-40.

Pericot, L., 1976, «Els meus records d'adolescent, alumne de l'institut de segon ensenyament a la Girona de l'actual segle», Revista de Gerona XXII, 121-123.

Peyró, P., 1897, «Lo que dice la prensa. Desde Sóller», Sóller. Semanario independiente. $2^{a}$ época XII (529. Sábado 22 de mayo de 1897), 1.

ReAder, A., 1924, «La astronomía en tiempos de los faraones», La Esfera Madrid, 22 de marzo 533, 12-13.

Rullán y Mir, J., 1898, «La antigüedad del hombre en la tierra y sus primeros pasos en las Baleares», Sóller. Semanario independiente. Ensayos Cientificos y Literarios Año XII, 2a época, n. ${ }^{o} 567$ (sábado, 12 de febrero de 1898), 3.

Rullán y Mir, J., 1900, Ensayos de Agricultura y Prehistoria, Sóller: Impr. de la Soledad.

Rullán y Mir, J., 1907, "Colaboración. Segunda Carta Abierta», Sóller. Semanario independiente

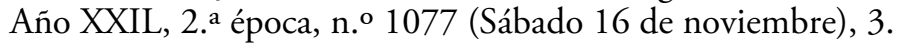

SaIz García, M. D., 1983, Historia del periodismo en España. Los origenes. El siglo XVIII, [Alianza Universidad Textos], Madrid: Alianza.

Salas Álvarez, J., 2012, "Protección y defensa del patrimonio arqueológico en Granada en el siglo XIX (1835-1884)», en: C. Papí Rodes, G. Mora, M. Ayarzagüena (eds.), El patrimonio arqueológico en España en el siglo XIX. El impacto de las desamortizaciones (pp. 350-374), Madrid: Ministerio de Educación, Cultura y Deporte, 64-82.

Salas Állvarez, J., 2015, "Acerca de las relaciones entre arqueología, patrimonio arqueológico y archivos. Estudio del caso madrileño a través de los fondos documentales conservados en la Real Academia de la Historia», en: N. Ávila Seoane (ed.), Madrid: su pasado documental, Madrid: Universidad Complutense de Madrid, 388-395.

Sánchez Moreno, A., 2018, «Del lugar donde fue Iliberri (Granada): historiografía de un debate», en: S. España-Chamorro, R. Arranz Santos, A. Romero Molero (eds.), Colecciones, arqueólogos, instituciones y yacimientos en la España de los siglos XVIII al XX. [Access Archaeology], Oxford: Archaeopress, 43-60.

Seco Álvarez, M., \& J. Martínez Babón, 2017, Tutankhamón en España: Howard Carter, el duque de Alba y las conferencias de Madrid, Editorial: Fundación José Manuel Lara.

Stone, P. G., 1989, «Interpretations and uses of the past in modern Britain and Europe. Why are people interested in the past? Do the expert know or care? A plea for further study», en: R. H. Layton (ed.), Who needs the past? Indigenous values and Archaeology. [One World Archaeology 5], London: Unwin Hyman, 195-206.

Tarradell, M., 1974, «Bosch Gimpera y la Escuela de Arqueología de Barcelona», Destino 26 octubre, 9-10. 
Ten, A. E., \& M. Cell Aragón (eds.), 1996, Catálogo de las revistas científicas y técnicas publicadas en España durante el siglo XIX, Valencia: Instituto de Estudios Documentales e Históricos sobre la Ciencia. Universidad de Valencia. CSIC.

Thornton, A., 2018, Archaeologists in Print: Publishing for the People, London: UCL Press.

Vallejo Girvés, M., 2012, «El Museo Arqueológico Complutense en el Archivo General Central de Alcalá de Henares: Fidel Fita, los archiveros y el papel de la prensa local en la polémica en torno a su autoría y gestación (1881-1883)», en: C. Papí Rodes, G. Mora, M. Ayarzagüena (eds.), El patrimonio arqueológico en España en el siglo XIX. El impacto de las desamortizaciones (pp. 350-374), Madrid: Ministerio de Educación, Cultura y Deporte, 227-255.

Zurinaga Fernández-Toribio, S., 2009a, El tratamiento de la información de la Campaña de Salvamento de Nubia en la prensa Española. 1959-1975, Madrid: DEA. Inédito. Departamento de Prehistoria. Facultad de Geografía e Historia. Universidad Complutense de Madrid.

Zurinaga Fernández-Toribio, S., 2009b, «La campaña de Nubia en la prensa española de la época. 1960-1966», Catálogo de la Exposición: 120 años de Arqueología española en Egipto. El Cairo, Madrid: Sociedad Estatal de Acción Cultural, Ministerio de Cultura, 47-53.

Zurinaga Fernández-Toribio, S., 2012, "Lo que dijeron los periódicos sobre la Campaña de Nubia», IV Congresso Ibérico de Egiptología. 13-17 Septiembre 2010. Lisboa, Lisboa: Museu de Farmácia. Museu das Comunicaçoes, 369-389.

Zurinaga Fernández-Toribio, S., 2015, «The Spanish Nubian Salvage Campaign through the Media and Official Archives», en: M. H. Zach (ed.), The Kushite world. Proceedings of the 11th International Conference for Meroitic Studies. Vienna, 1-4 september 2008. [Beiträge zur Sudanforschung. Beiheft 9], Viena: Verein der Förderer der Sudanforschung: 613-622.

Zurinaga Fernández-Toribio, S., 2017, Arqueología del Oasis. España en la Campaña de Salvamento de la Unesco en Nubia, 1960-1972, Madrid: Tesis doctoral. Universidad Complutense de Madrid. 